\title{
OPTIMALISASI FORMULASI MINUMAN JELLY LIDAH BUAYA (Aloe vera L.) DAN DAUN BLACK MULBERRY (Morus nigra L.) MENGGUNAKAN DESIGN EXPERT METODE MIXTURE D-OPTIMAL
}

\author{
Yusman Taufik \\ Tantan Widiantara \\ Syarifah Ulfah

\begin{abstract}
Program Studi Teknologi Pangan, Fakultas Teknik, Universitas Pasundan, Jl. Dr.Setiabudi No 93, Bandung, 40153, Indonesia

E-mail : yusmantaufik@unpas.ac.id
\end{abstract}

\begin{abstract}
Abstrak
Tujuan dilakukan penelitian ini adalah untuk memperoleh formulasi optimal dalam pembuatan minuman jelly lidah buaya dan daun black mulberry menggunakan program Design Expert metode Mixture D-Optimal. Penelitian ini meliputi lima tahap yaitu analisis bahan baku, penentuan variabel dan penentuan respon, penentuan formulasi dengan Design Expert metode Mixture D-Optimal, pembuatan produk dan pengujian respon produk minuman jelly lidah buaya dan daun black mulberry dengan formulasi dari program Design Expert metode Mixture D-Optimal, tahap terakhir penentuan formulasi terpilih dan pengujian formulasi terpilih. Formulasi optimal yang telah diprediksi oleh program Design Expert metode Mixture D-Optimal memiliki nilai ketepatan (desirability) 0,699 dengan kadar air 80,44\%, kadar vitamin C 13,14 mg/100g, pH 5,1, viskositas 270 mpas, sineresis 6,78\%, uji hedonik atribut warna 3,45, atribut aroma 3,32, atribut rasa 3,72, dan atribut tekstur 4,2. Berdasarkan hasil tersebut menunjukkan bahwa program Design Expert metode Mixture D-Optimal dapat menentukan formulasi optimal minuman jelly lidah buaya dan daun black mulberry..
\end{abstract}

\begin{abstract}
The purpose of this research was to get optimal formulation in making jelly drink aloe vera and black mulberry leaf using Design Expert method of Mixture D-Optimal. The research was conducted in five stages: raw material analysis, variable determination and response determination, formulation determination with Experimental Design Expert method of Mixture D-Optimal, product manufacture and response test of jelly drink Aloe vera and black mulberry leaf with formulation from Design Expert method of Mixture D-Optimal, final step selected optimal formulation and optimal formulation test. The optimal formulation predicted by program Design Expert method Mixture D-optimum has a desirability value of 0.699 with moisture content of $80.44 \%$, vitamin C level $13.14 \mathrm{mg} / 100 \mathrm{~g}$, pH 5.1, viscosity 270 mpas, sineresis $6,78 \%$, color hedonik test attribute 3.45, attribute scent 3.32, flavor attribute 3.72, and texture attribute 4.2. Based on the results, program Design Expert Mixture D-optimum can determine the optimal formulation of aloe vera beverage and black mulberry leaf.

Keywords: Jelly drink, Aloe vera, Black mulberry leaf.
\end{abstract}

\section{Pendahuluan}

Lidah buaya (Aloe vera) merupakan salah satu komoditas pertanian daerah tropis yang memiliki potensi untuk dikembangkan sebagai usaha agroindustri. Produksi lidah buaya dari tahun ke tahun mengalami peningkatan. Menurut data statistik produksi hortikultura (2015), produksi tanaman lidah buaya pada tahun 2009 berjumlah $2.903 .138 \mathrm{~kg}$ sedangkan produksi tanaman lidah buaya pada tahun 2014 berjumlah $15.191 .612 \mathrm{~kg}$. Tanaman lidah buaya dengan produksi terbesar berada di provinsi Kalimantan Barat dengan jumlah produksi sebesar $12.384 .210 \mathrm{~kg}$.

Lidah buaya mengandung mineral seperti $\mathrm{Zn}, \mathrm{K}$, dan Fe, serta vitamin seperti A, B1, B2, B12, C, E, inositol, asam folat, dan kholin. Dengan kandungan nutrisi tersebut maka peluang diversifikasi produk lidah buaya sangat besar. Salah satunya sebagai minuman jelly. Untuk meningkatkan kandungan antioksidan, dilakukan penambahan daun black mulberry pada minuman jelly tersebut.

Daun black mulberry merupakan bagian dari tanaman black mulberry yang banyak dimanfaatkan dalam pengembangbiakan ulat sutera dan pemanfaatan untuk olahan pangan masih sangat minim. Daun black mulberry kaya akan kandungan flavonoid yang memiliki aktivitas biologis yang termasuk dalam hal aktivitas antioksidan.

Hasil penelitian menunjukkan bahwa daun black mulberry terdapat aktivitas antioksidan yang kuat dengan nilai IC50 dari 89,43 $\pm 37,65$ ppm. Selain itu daun black mulberry mengandung sejumlah klorofil, dengan tingkat kematangan lama sebesar 2,64 mg/g, tingkat kematangan medium sebesar $4,15 \mathrm{mg} / \mathrm{g}$, dan daun muda sebesar $3,32 \mathrm{mg} / \mathrm{g}$. Ekstrak dari varietas 
daun black mulberry mengandung fenol total 24,37 $\mathrm{mg} / \mathrm{g}$ dan flavonoid total $30 \mathrm{mg} / \mathrm{g}$ (Taufik dkk, 2016).

Minuman jelly adalah produk minuman yang berbentuk gel, yang dapat dibuat dari pektin, agar, karagenan, gelatin, atau seyawa hidrokoloid lainnya dengan penambahan gula, asam, dan atau tanpa bahan tambahan makanan lain yang diizinkan. Minuman jelly memiliki konsistensi gel yang lemah sehingga memudahkan untuk disedot sebagai minuman (Noer 2006).

Penentuan optimalisasi formulasi dapat dilakukan dengan berbagai metode diantaranya metode simplex dengan pemograman linier, software lindo, fasilitas solver pada Microsoft Excel, dan Design Expert metode Mixture D-optimal (Wulandari, 2016).

Design Expert digunakan untuk optimasi proses dalam respon utama yang diakibatkan oleh beberapa variabel dan tujuannya adalah optimasi respon tersebut. Design Expert menyediakan beberapa pilihan desain dengan fungsinya masing-masing, salah satunya adalah Mixture Design yang berfungsi untuk menemukan formulasi optimal (Bas dan Boyaci, 2007 dalam Wulandari, 2016.

\section{Bahan dan Metode Penelitian}

Bahan yang digunakan adalah lidah buaya varietas Aloe chinensis yang berumur 10 bulan dari perkebunan Aloe vera Centre di Pontianak, daun black mulberry varietas Morus nigra dengan pemetikan $\mathrm{p}+2$ yang berumur 2 bulan dari perkebunan Cibodas di Lembang, air, karagenan dan sukrosa dari toko Sejati di Bandung.

Bahan yang digunakan untuk analisis adalah alkohol 70\%, toluen, aquadest, larutan luff schoorl, $\mathrm{KIO}_{3}, \mathrm{H}_{2} \mathrm{SO}_{4} 6 \mathrm{~N}, \mathrm{Na}_{2} \mathrm{~S}_{2} \mathrm{O}_{3} 0,1 \mathrm{~N}$, amilum $1 \%, \mathrm{HCl} 9,5 \mathrm{~N}$, metanol, DPPH (2,2-Dipenyl-1-picrylhdrazyl), kertas saring, dan $\mathrm{I}_{2}$ 0,01 yang diperoleh dari Laboratorium Teknologi Pangan Universitas Pasundan, Bandung.

Alat yang digunakan adalah blender (phillips), saringan, wadah, panci, batang pengaduk (pyrex), timbangan digital (ohaus), kompor gas (rinnai), cup plastik, dan termometer (pyrex).

Alat yang digunakan untuk analisis adalah timbangan digital (ohaus), destilator (thermo), refluks, viskometer, labu takar (pyrex), pipet, filler, bunsen, buret (pyrex), statif, erlenmeyer (pyrex), cawan porselen, oven, desikator, dan $\mathrm{pH}$ meter (schoot).

Tahap I. Analisis Bahan Baku

Analisis yang akan dilakukan diantaranya analisis kadar air metode destilasi untuk lidah buaya, analisis kadar air metode gravimetri untuk daun black mulberry, analisis vitamin $\mathrm{C}$ metode iodimetri, pengukuran $\mathrm{pH}$, analisis kadar gula total, dan analisis antioksidan.

Tahap II. Penentuan Variabel dan Penentuan Respon

Bahan-bahan yang digunakan sebagai variabel berubah yaitu daging lidah buaya dengan batas atas hingga batas bawahnya 17,56-43,4\%, ekstrak daun black mulberry dengan batas atas hingga batas bawahnya $0,5-7 \%$, dan air dengan batas atas hingga batas bawahnya 43,9-69,74\% . Sedangkan untuk variabel tetapnya adalah karagenan $0,2 \%$ dan sukrosa $12 \%$.

Respon yang digunakan yaitu analisis kadar air, analisis vitamin $\mathrm{C}$, pengukuran $\mathrm{pH}$, viskositas, sineresis, dan uji hedonik (kesukaan) dengan atribut warna, aroma, rasa, dan tekstur.

Tahap III. Penentuan Formulasi dengan Design Expert metode Mixture D-Optimal

Penentuan formulasi menggunakan aplikasi Design Expert dengan memasukkan data variabel bebas dan respon yang telah ditentukan sebelumnya.

Tahap IV : Pembuatan dan Pengujian Respon Produk Minuman Jelly Lidah Buaya dan Daun Black Mulberry dengan Formulasi dari Program Design Expert Metode Mixture D-Optimal

Produk Minuman Jelly Lidah Buaya dan Daun Black Mulberry dilakukan pengujian kimia, pengujian fisik, dan pengujian organolepik. Data hasil pengujian dimasukan ke setiap kolom respon untuk melakukan optimasi formula dengan program Design Expert Metode Mixture D-Optimal.

Tahap V. Penentuan Formula Terpilih dan Pengujian Formula Terpilih

Data hasil analisis kemudian dioptimasi dengan program Design Expert Metode D-Optimal untuk mendapatkan suatu formula terpilih, formula terpilih kemudian akan dilakukan pengujian kembali sesuai dengan respon-respon yang ditentukan beserta analisis kadar gula total dan analisis antioksidan.

\section{Hasil dan Pembahasan}

Hasil Penelitian Tahap Pertama

Hasil yang didapatkan dari analisis kimia bahan baku disajikan pada Tabel 1.

Tabel 1. Hasil Analisis Kimia Bahan Baku

\begin{tabular}{|c|c|c|}
\hline Analisis & $\begin{array}{c}\text { Daun Black } \\
\text { Mulberry }\end{array}$ & Lidah Buaya \\
\hline Kadar Air & $68,65 \%$ & $98,93 \%$ \\
\hline Kadar Vitamin C & $13,16 \mathrm{mg} / 100 \mathrm{~g}$ & $3,5 \mathrm{mg} / 100 \mathrm{~g}$ \\
\hline $\mathrm{pH}$ & 5,83 & 4,02 \\
\hline Kadar Gula Total & $2,61 \%$ & $0,57 \%$ \\
\hline Aktivitas Antioksidan & $862,79 \mathrm{ppm}$ & $167877 \mathrm{ppm}$ \\
\hline
\end{tabular}

\section{Hasil Penelitian Tahap Kedua}

Hasil penentuan variabel dan penentuan respon yag akan digunakan pada penelitian Tahap III disajikan pada Tabel 2.

Tabel 2. Variabel Berubah dan Variabel Tetap

\begin{tabular}{|c|c|}
\hline Variabel Berubah & Variabel Tetap \\
\hline Ekstrak daun black & Karagenan \\
mulberry & Sukrosa \\
Lidah buaya & \\
Air & \\
\hline
\end{tabular}

Hasil Penelitian Tahap Ketiga 
Formulasi minuman jelly lidah buaya dan daun black mulberry yang berdasarkan Program Design Expert metode Mixture D-Optimal dapat dilihat pada Tabel 3.

Tabel 3. Formulasi Minuman Jelly Lidah Buaya dan Daun Black Mulberry

\begin{tabular}{|c|c|c|c|}
\hline Formulasi & $\begin{array}{c}\text { Ekstrak Daun } \\
\text { Black Mulberry }\end{array}$ & $\begin{array}{c}\text { Daging } \\
\text { Lidah Buaya }\end{array}$ & Air \\
\hline F1 & $0,501 \%$ & $43,399 \%$ & $43,900 \%$ \\
\hline F2 & $6,991 \%$ & $29,492 \%$ & $51,317 \%$ \\
\hline F3 & $4,739 \%$ & $22,329 \%$ & $60,732 \%$ \\
\hline F4 & $7,000 \%$ & $36,680 \%$ & $44,120 \%$ \\
\hline F5 & $3,745 \%$ & $35,431 \%$ & $48,624 \%$ \\
\hline F6 & $2,667 \%$ & $32,443 \%$ & $52,691 \%$ \\
\hline F7 & $0,500 \%$ & $30,375 \%$ & $56,925 \%$ \\
\hline F8 & $7,000 \%$ & $24,299 \%$ & $56,501 \%$ \\
\hline F9 & $7,000 \%$ & $17,971 \%$ & $62,829 \%$ \\
\hline F10 & $0,500 \%$ & $24,043 \%$ & $63,257 \%$ \\
\hline F11 & $0,505 \%$ & $17,560 \%$ & $69,735 \%$ \\
\hline
\end{tabular}

\section{Hasil Penelitian Tahap Keempat}

\section{Kadar Air}

Data hasil perhitungan ANAVA menunjukkan bahwa respon kadar air minuman jelly lidah buaya dan daun black mulberry, hasil analisis menunjukkan bahwa respon kadar air dari 11 formulasi berpengaruh dengan nilai probabilitas lebih kecil dari 0,05 yaitu 0,0001 .

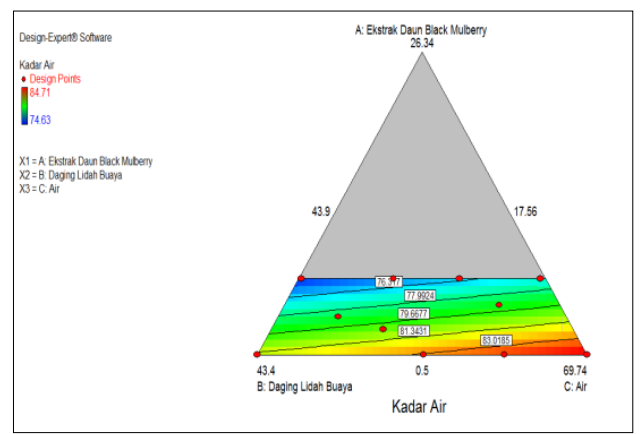

Gambar 1. Grafik Design Expert 11 Formulasi Minuman Jelly Lidah Buaya dan Daun Black Mulberry Berdasarkan Respon Kadar Air

Grafik Design Expert dengan nilai respon tertinggi ditunjukkan dengan warna merah yang berada pada sudut variabel c (komponen air), hal ini menunjukkan peningkatan kadar air dipengaruhi oleh penambahan jumlah air. Peningkatan kadar air juga berasal dari bahan baku lidah buaya. Hal ini sesuai dengan pernyataan Antarwinarya (2013), bahwa semakin meningkatnya jumlah lidah buaya yang digunakan, semakin meningkat kadar air produk.

\section{Kadar Vitamin C}

Data hasil perhitungan ANAVA menunjukkan bahwa respon kadar vitamin $\mathrm{C}$ minuman jelly lidah buaya dan daun black mulberry, hasil analisis menunjukkan bahwa respon kadar vitamin $\mathrm{C}$ dari 11 formulasi berpengaruh dengan nilai probabilitas lebih kecil dari 0,05 yaitu 0,0001 .

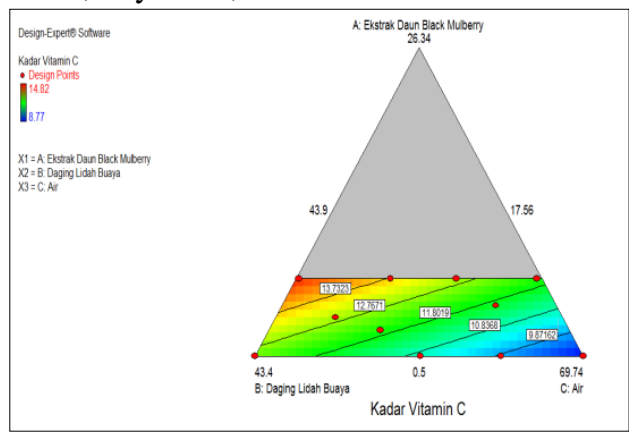

Gambar 2. Grafik Design Expert 11 Formulasi Minuman Jelly Lidah Buaya dan Daun Black Mulberry Berdasarkan Respon Vitamin C

Grafik Design Expert dengan nilai respon tertinggi ditunjukkan dengan warna merah yang berada diantara variabel a (komponen ekstrak daun black mulberry) dan variabel $b$ (daging lidah buaya). Kombinasi penambahan ekstrak daun black mulberry dan lidah buaya memberikan hasil respon kadar vitamin $\mathrm{C}$ yang berbeda-beda. Semakin tinggi ekstrak daun black mulberry dan lidah buaya yang ditambahkan maka kadar vitamin $\mathrm{C}$ semakin tinggi. Penambahan air juga mempengaruhi kadar vitamin $\mathrm{C}$ minuman jelly lidah buaya dan daun black mulberry. Semakin banyak air yang ditambahkan maka kadar vitamin $\mathrm{C}$ semakin rendah.

3. $\mathrm{pH}$

Data hasil perhitungan ANAVA menunjukkan bahwa respon $\mathrm{pH}$ minuman jelly lidah buaya dan daun black mulberry, hasil analisis menunjukkan bahwa respon $\mathrm{pH}$ dari 11 formulasi berpengaruh dengan nilai probabilitas lebih kecil dari 0,05 yaitu 0,0002.

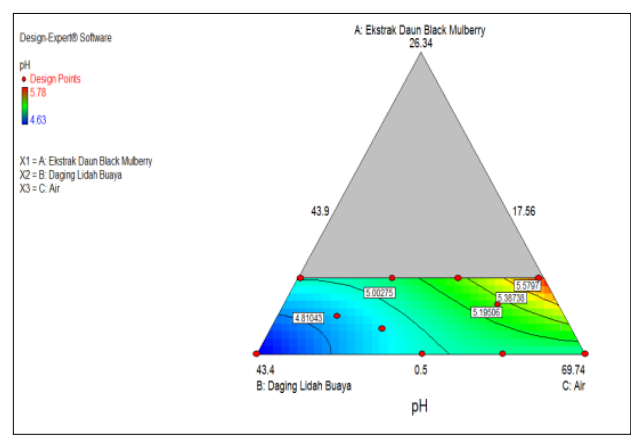

Gambar 3. Grafik Design Expert 11 Formulasi Minuman Jelly Lidah Buaya dan Daun Black Mulberry Berdasarkan Respon $\mathrm{pH}$

Grafik Design Expert dengan nilai respon tertinggi ditunjukkan dengan warna merah yang berada diantara variabel a (komponen ekstrak daun black mulberry) dan variabel c (komponen air). pH pada minuman jelly mempengaruhi viskositas, sineresis, dan pembentukan gel. Nilai $\mathrm{pH}$ yang terlalu rendah akan menimbulkan sineresis. Karagenan memiliki kestabilan 
gel pada $\mathrm{pH} 7$, sedangkan pada $\mathrm{pH}$ di bawah 4,3 kekuatan gel dan viskositasnya akan menurun (Winarno, 2008).

\section{Viskositas}

Data hasil perhitungan ANAVA menunjukkan bahwa respon viskositas minuman jelly lidah buaya dan daun black mulberry, hasil analisis menunjukkan bahwa respon viskositas dari 11 formulasi berpengaruh dengan nilai probabilitas lebih kecil dari 0,05 yaitu 0,0243 .

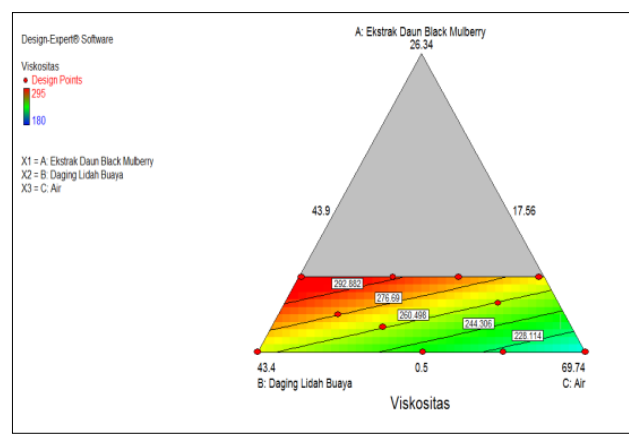

Gambar 4. Grafik Design Expert 11 Formulasi Minuman Jelly Lidah Buaya dan Daun Black Mulberry Berdasarkan Respon Viskositas

Grafik Design Expert dengan nilai respon tertinggi ditunjukkan dengan warna merah yang berada diantara variabel a (komponen ekstrak daun black mulberry) dan variabel b (daging lidah buaya). Viskositas adalah derajat kekentalan suatu produk pangan. Viskositas minuman jelly dipengaruhi oleh suatu hidrokoloid, dan molekul-molekul lain. Hidrokoloid yang digunakan yaitu karagenan yang merupakan bahan pembentuk gel. Karagenan stabil pada $\mathrm{pH}$ 3,5-4, penurunan $\mathrm{pH}$ menyebabkan hidrolisis polimer karagenan, yang mengakibatkan kehilangan viskositas (Glicksman, 1983). Selain itu penambahan air yang terdapat pada ketiga variabel berubah juga mempengaruhi viskositas minuman jelly.

\section{Sineresis}

Data hasil perhitungan ANAVA menunjukkan bahwa respon sineresis minuman jelly lidah buaya dan daun black mulberry, hasil analisis menunjukkan bahwa respon sineresis dari 11 formulasi berpengaruh dengan nilai probabilitas lebih kecil dari 0,05 yaitu 0,0009 .

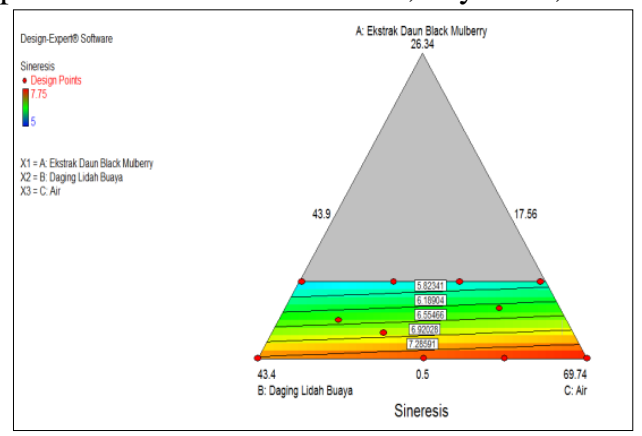

Gambar 5. Grafik Design Expert 11 Formulasi Minuman Jelly Lidah Buaya dan Daun Black Mulberry Berdasarkan Respon Sineresis

Grafik Design Expert dengan nilai respon tertinggi ditunjukkan dengan warna merah yang berada pada sudut variabel c (komponen air), hal ini menunjukkan peningkatan sineresis dipengaruhi oleh penambahan jumlah air. Sineresis pada minuman jelly merupakan suatu proses yang diharapkan agar minuman jelly lebih mudah disedot, akan tetapi jumlahnya tidak terlalu banyak karena dapat menyebabkan penurunan mutu. Kombinasi bahan baku variabel berubah yang ditambahkan air, menunjukkan bahwa air mempengaruhi nilai sineresis.

6. Respon Organoleptik

a. Warna

Data hasil perhitungan ANAVA menunjukkan bahwa respon warna minuman jelly lidah buaya dan daun black mulberry, hasil analisis menunjukkan bahwa respon warna dari 11 formulasi berpengaruh dengan nilai probabilitas lebih kecil dari 0,05 yaitu 0,0025 .

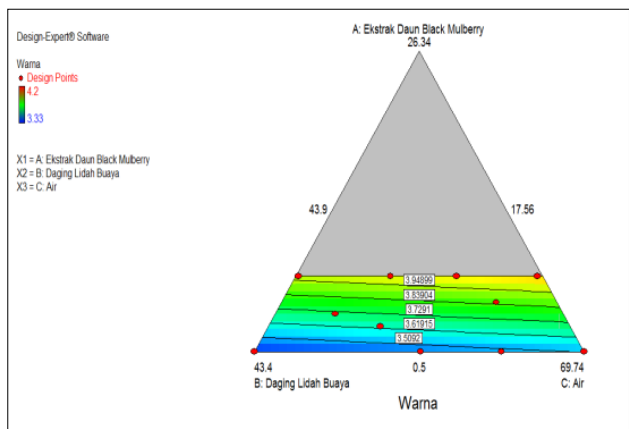

Gambar 6. Grafik Design Expert 11 Formulasi Minuman Jelly Lidah Buaya dan Daun Black Mulberry Berdasarkan Respon Warna

Grafik Design Expert dengan nilai respon tertinggi ditunjukkan dengan warna kuning yang berada diantara variabel a (komponen ekstrak daun black mulberry) dan variabel c (komponen air). Nilai kesukaan terhadap warna menunjukkan bahwa panelis memberi penilaian dari agak tidak suka hingga agak suka terhadap warna minuman jelly lidah buaya dan daun black mulberry. Warna yang terdapat pada minuman jelly lidah buaya dan daun black mulberry berasal dari ekstrak daun black mulberry dan lidah buaya yang ditambahkan.

\section{b. Aroma}

Data hasil perhitungan ANAVA menunjukkan bahwa respon aroma minuman jelly lidah buaya dan daun black mulberry, hasil analisis menunjukkan bahwa respon aroma dari 11 formulasi berpengaruh dengan nilai probabilitas lebih kecil dari 0,05 yaitu 0,0269 . 


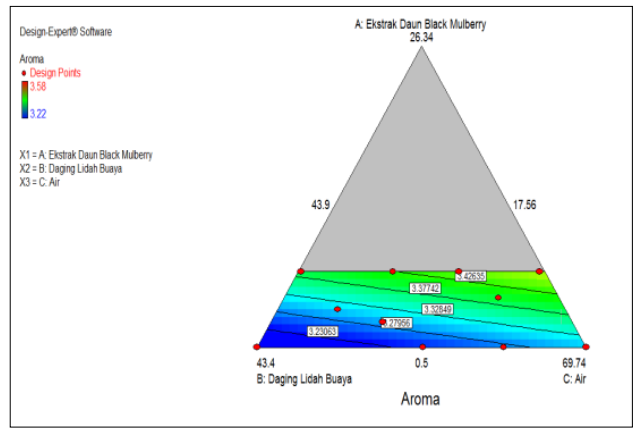

Gambar 7. Grafik Design Expert 11 Formulasi Minuman Jelly Lidah Buaya dan Daun Black Mulberry Berdasarkan Respon Aroma

Grafik Design Expert dengan nilai respon tertinggi ditunjukkan dengan warna hijau yang berada diantara variabel a (komponen ekstrak daun black mulberry) dan variabel c (komponen air). Nilai kesukaan terhadap aroma menunjukkan bahwa panelis memberi penilaian agak tidak suka terhadap aroma minuman jelly lidah buaya dan daun black mulberry. Aroma yang terdapat pada minuman jelly lidah buaya dan daun black mulberry berasal dari ekstrak daun black mulberry dan lidah buaya yang ditambahkan.

c. Rasa

Data hasil perhitungan ANAVA menunjukkan bahwa respon rasa minuman jelly lidah buaya dan daun black mulberry, hasil analisis menunjukkan bahwa respon rasa dari 11 formulasi tidak berpengaruh dengan nilai probabilitas lebih besar dari 0,05 yaitu 0,4828 .

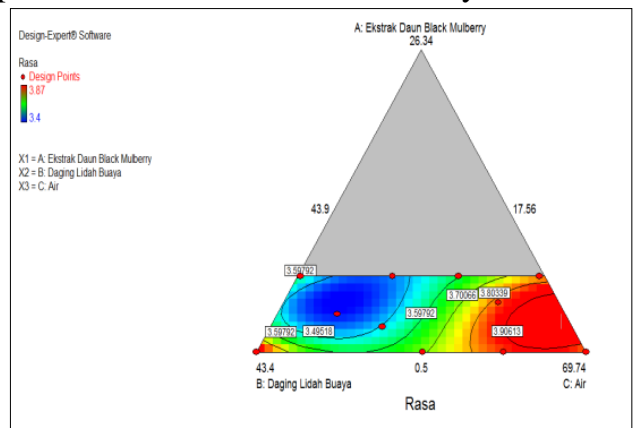

Gambar 8. Grafik Design Expert 11 Formulasi Minuman Jelly Lidah Buaya dan Daun Black Mulberry Berdasarkan Respon Rasa

Grafik Design Expert dengan nilai respon tertinggi ditunjukkan dengan warna merah yang berada diantara ketiga variabel a (komponen ekstrak daun black mulberry), b(daging lidah buaya), dan c (komponen air). Nilai kesukaan terhadap rasa menunjukkan bahwa panelis memberi penilaian agak tidak suka terhadap rasa minuman jelly lidah buaya dan daun black mulberry. Rasa manis yang terdapat pada minuman jelly lidah buaya dan daun black mulberry berasal dari gula yang ditambahkan. Hasil respon menunjukkan hasil yang tidak berbeda jauh dikarenakan jumlah gula yang ditambahkan sama.

\section{d. Tekstur}

Data hasil perhitungan ANAVA menunjukkan bahwa respon tekstur minuman jelly lidah buaya dan daun black mulberry, hasil analisis menunjukkan bahwa respon tekstur dari 11 formulasi berpengaruh dengan nilai probabilitas lebih kecil dari 0,05 yaitu 0,0106 .

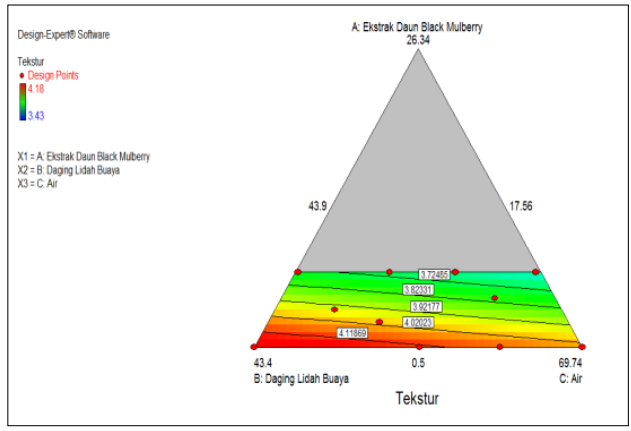

Gambar 9. Grafik Design Expert 11 Formulasi Minuman Jelly Lidah Buaya dan Daun Black Mulberry Berdasarkan Respon Tekstur

Grafik Design Expert dengan nilai respon tertinggi ditunjukkan dengan warna merah yang berada pada sudut variabel b (komponen daging lidah buaya), hal ini menunjukkan peningkatan tekstur dipengaruhi oleh penambahan jumlah daging lidah buaya. Nilai kesukaan terhadap tekstur menunjukkan bahwa panelis memberi penilaian agak tidak suka hingga agak suka terhadap tekstur minuman jelly lidah buaya dan daun black mulberry. Tekstur yang terdapat pada minuman jelly lidah buaya dan daun black mulberry berasal dari karagenan dan kombinasi variabel lain yang ditambahkan air.
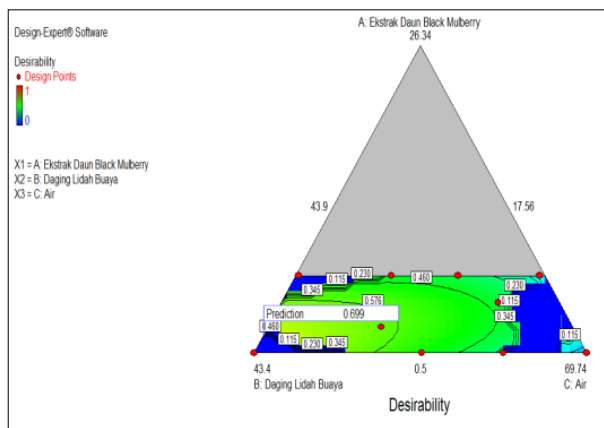

Gambar 10. Grafik Desirability Formulasi Terpilih Minuman Jelly Lidah Buaya dan Daun Black Mulberry

Program Design Expert metode Mixture DOptimal memberikan 1 solusi formula optimal dengan nilai desirability yaitu 0,699 . Ketepatan formulasi dan nilai masing-masing respon tersebut dapat dilihat pada desirability. Desirability adalah derajat ketepatan hasil solusi atau formulasi optimal. Semakin mendekati nilai satu maka semakin tinggi nilai ketepatan formulasi, sehingga dapat disimpulkan berdasarkan nilai desirability yang telah mencapai 1,00 maka nilai respon memiliki ketepatan yang tinggi (Nugraha, 2014). 
Tabel 4. Perbandingan dan Standar Deviasi Hasil Analisis Design Expert dengan Hasil Analisis Laboratorium Formulasi Terpilih Minumaman Jelly Lidah Buaya dan Daun Black Mulberry.

\begin{tabular}{|c|c|c|c|}
\hline Respon & $\begin{array}{c}\text { Design } \\
\text { Expert }\end{array}$ & Laboratorium & $\begin{array}{c}\text { Standar } \\
\text { Deviasi }\end{array}$ \\
\hline Kadar air & $79,86 \%$ & $80,44 \%$ & 0,41 \\
\hline $\begin{array}{c}\text { Kadar vitamin } \\
\mathrm{C}\end{array}$ & $\begin{array}{c}13,01 \mathrm{mg} / 100 \\
\mathrm{~g}\end{array}$ & $\begin{array}{c}13,14 \\
\mathrm{mg} / 100 \mathrm{~g}\end{array}$ & 0,09 \\
\hline $\mathrm{pH}$ & 4,7 & 5,1 & 0,28 \\
\hline Viskositas & 274,7 & 270 & 3,32 \\
\hline Sineresis & 7,07 & 6,78 & 0,21 \\
\hline Warna & 3,44 & 3,45 & 0,01 \\
\hline Aroma & 3,29 & 3,32 & 0,02 \\
\hline Rasa & 3,76 & 3,72 & 0,03 \\
\hline Tekstur & 4,22 & 4,2 & 0,01 \\
\hline
\end{tabular}

Selain dilakukan pengujian respon tersebut, dilakukan analisis aktivitas antioksidan dan kadar gula total pada formulasi terpilih. Aktivitas antioksidan formulasi terpilih dengan nilai $\mathrm{IC}_{50}$ sebesar 26926 ppm.

Nilai IC $_{50}$ merupakan konsentrasi larutan substrat atau sampel yang mampu mereduksi aktivitas DPPH sebesar $50 \%$ atau dapat dikatakan bilangan yang menunjukkan konsentrasi (ppm) yang mampu menghambat proses oksidasi sebesar $50 \%$. Nilai aktivitas antioksidan dari produk minuman jelly lidah buaya dan daun black mulberry formulasi terpilih yang dinyatakan dengan nilai $\mathrm{IC}_{50}$ adalah 26926 ppm termasuk dalam kategori sangat lemah karena berada pada nilai $\mathrm{IC}_{50}$ lebih dari $600 \mathrm{ppm}$.

Kadar gula total merupakan kandungan gula keseluruhan dalam suatu bahan pangan yang terdiri dari gula pereduksi dan gula non-pereduksi, jenis gula total yaitu dari golongan monosakarida, disakarida, oligosakarida, dan polisakarida. Sehingga yang terhitung pada kadar gula total tidak hanya gula yang dapat mereduksi saja namun gula non-pereduksi juga akan terhitung (Rohman dan Soemantri, 2007). Berdasarkan hasil analisis laboratorium, kadar gula total formulasi terpilih sebesar $13,1 \%$.

Berdasarkan hasil penelitian, dapat diambil kesimpulan sebagai berikut :

1. Berdasarkan hasil penelitian, program Design Expert metode Mixture D-Optimal dapat menentukan formulasi optimal terhadap karakteristik minuman jelly lidah buaya dan daun black mulberry dengan karakteristik respon yang telah sesuai dengan standar produk sejenis. Respon yang berpengaruh terhadap 11 formulasi produk yaitu kadar air, kadar vitamin $\mathrm{C}, \mathrm{pH}$, viskositas, sineresis, warna, aroma, dan tekstur.

2. Berdasarkan data 11 formulasi produk, diperoleh satu formulasi optimal yang telah diprediksi oleh program Design Expert metode Mixture D-optimal yang memiliki nilai ketepatan (desirability) 0,699 dengan kadar air 80,44\%, kadar vitamin C 13,14 $\mathrm{mg} / 100 \mathrm{~g}$, pH 5,1, viskositas 270 mpas, sineresis $6,78 \%$, uji hedonik atribut warna 3,45 , atribut aroma 3,32, atribut rasa 3,72, dan atribut tekstur 4,2 .

\section{Daftar Pustaka}

1. Antawinarya. 2013. Pengaruh Perbandingan Jumlah Tepung Ketan Dengan Lidah Buya (Aloe Barbandesis Miller) Terhadap Karakteristik Dodol Lidah Buaya. Universitas Udayana. Bali.

2. Glicksman, M. 1983. Seawed extrac. In: Food Hydrocolloids Vol II. CRC Press. Florida.

3. Kementrian Pertanian. 2015. Statistik Produksi Hortikultura. Direktorat Jendral Hortikultura. Jakarta.

4. Nugroho, A. 2012. Pemanfaatan Software dalam Penelitian. Universitas Gajah Mada. Yogyakarta.

5. Noer, H. 2006. Hidrokoloid dalam Pembuatan Jelly Drink. Food Review Vol. 1. Jakarta.

6. Rohman, A. Soemantri. 2007. Analisis Makanan. Universitas Gadjah Mada. Jawa Tengah

7. Taufik, Yusman. Widiantara, Tantan. Garnida, Yudi. The Effect Of Drying Temperature On The Antioxidant Activity Of Black Mulberry Leaf Tea (Morus nigra). Rasayan J. Chem Vol. 9. Universitas Pasundan. Bandung.

8. Winarno FG. 2008. Kimia Pangan dan Gizi. MBrio Press. Bogor.

9. Wulandari, Tenri. Ghozali, Thomas. Taufik, Yusman. 2016. Optimalisasi Formulasi Minuman Fungsional Black Mulberry (Morus nigra L) Dengan Design Expert Metode Mixture D-Optimal Universitas Pasundan. Bandung. 